\title{
Deteksi Kerusakan dan Penempatan Sensor Percepatan Berbasis Respons Dinamis Struktur: Kasus Jembatan KA Porong, Sidoarjo
}

\author{
Tri Susanto, Agung Budipriyanto \\ Program Studi Diploma Teknik Sipil FTSP ITS, Surabaya \\ Email: agungbp@ce.its.ac.id
}

\begin{abstract}
Many steel truss bridges in Indonesia were built decades ago. To ensure that the bridge structure is in-service conditions, periodic monitoring is required. Thus, structural health of the bridge can be assessed and collapse of the structure can be avoided. This paper presents the results of a study on structural damage detection of a steel truss railway bridge. The bridge is located in Porong, Sidoarjo. It was built during the Dutch colonial era. The vibration based damage identification method was applied to identify the simulated structural damages occurred in the bridge. In this study the structure was modeled numerically using commputer software for facilitating in obtaining its dynamic characteristics under passing train loads. In addition a method for determining the optimal location of acceleration sensors was adopted. The results of the study showed that the methods used in this study could detect the occasion of the simulated damages occurred in the structure and establish the optimal sensor locations.
\end{abstract}

Keywords: structural damage detection, dynamic parameters of structures, acceleration sensors placement

Abstrak

Tidak sedikit jembatan rangka baja di Indonesia yang dibangun beberapa puluh tahun lalu. Agar struktur jembatan tersebut tetap dalam kondisi layan, maka monitoring struktur secara periodik sangat diperlukan sehingga keruntuhan struktur jembatan dapat dihindari. Makalah ini menyajikan hasil studi deteksi kerusakan struktur jembatan rangka baja kereta api. Jembatan terletak di Porong, Sidoarjo dan dibangun sejak era kolonial Belanda. Metode deteksi kerusakan struktur berbasis getaran diaplikasikan untuk mengidentifikasi kerusakan yang disimulasikan. Untuk memperoleh karakteristik dinamisnya akibat beban kereta yang lewat, struktur tersebut dimodelkan secara numerik dengan perangkat lunak komputer. Struktur tersebut dimodelkan baik dalam kondisi utuh atau terdapat kerusakan. Metode penempatan sensor akselerometer juga diaplikasikan pada jembatan ini. Hasil studi ini menunjukkan bahwa metode yang digunakan mampu mendeteksi pengaruh kerusakan yang disimulasikan terjadi pada struktur dan menentukan lokasi penempatan sensor yang optimal.

Kata kunci: deteksi kerusakan struktur, parameter dinamis, penempatan sensor percepatan.

\section{Pendahuluan}

Indonesia sebagai negara kepulauan memiliki topografi yang unik berupa daratan-daratan yang dipisahkan oleh perairan dan sungai. Kondisi inilah yang membuat Indonesia mem-butuhkan jembatan sebagai salah satu infrastruktur penting dalam menunjang perekonomian di Indonesia.

Dari ribuan jembatan di Indonesia, tidak sedikit jembatan yang merupakan jembatan rangka baja. Jembatan tersebut perlu mendapat perhatian bukan saja dalam tahap perencanaan dan pelaksanaan, namun yang lebih utama dalam masa pemeliharaan selama umur rencananya. Mengingat pembangunan jembatan rangka baja di Indonesia sudah dimulai sejak penjajahan Belanda, maka agar struktur jembatan tersebut tetap dalam kondisi layan, monitoring struktur jembatan secara periodik sangat diperlukan. Monitoring struktur secara rutin perlu dilakukan sehingga jembatan rangka baja dapat berfungsi dengan baik 
pada umur rencananya dan keruntuhan jembatan secara tiba-tiba dapat dihindari.

Pedoman Konstruksi Bangunan No. 005/BM/2009 menjelaskan bahwa ada berbagai jenis monitoring kelayakan struktur secara visual (visual inspection) terhadap jembatan yang merupakan bagian dari proses pemeliharaan jembatan rangka baja di Indonesia. Jenisjenis pemeriksaan tersebut antara lain pemeriksaan inventaris, pemeriksaan detail, dan pemeriksaan khusus. Pemeriksaan inventarisasi adalah pengumpulan data administrasi, geometri, material, dan data tambahan lainnya pada setiap jembatan, termasuk lokasi jembatan, panjang bentang, dan jenis konstruksi untuk setiap bentang. Pemeriksaan detail mendata semua kerusakan yang berarti pada elemen jembatan dan ditandai dengan nilai kondisi untuk setiap elemen, kelompok elemen, dan komponen utama jembatan. Nilai kondisi jembatan secara keseluruhan didapat dari nilai kondisi setiap elemen jembatan. Pemeriksaan khusus biasanya disarankan oleh pemeriksa jembatan pada waktu pemeriksaan detail karena pemeriksa merasa kurangnya data atau kendala lain untuk menentukan kondisi jembatan.

Pada beberapa dekade terakhir telah dikembangkan metode identifikasi kerusakan struktur berbasis karakteristik dinamis struktur. Metode ini merupakan salah satu metode pemeriksaan tidak merusak atau Non-Destructive Testing, (NDT). Dengan menggunakan data karakteristik dinamis struktur yang ele- mennya telah mengalami kerusakan, maka kerusakan struktur dapat diidentifikasi dan lokasinya diestimasikan sehingga strategi untuk perbaikan struktur dapat direncananan.

Menurut Ge dan Lui (2005) metode identifikasi kerusakan struktur dengan parameter modal dibedakan menjadi dua yaitu (a) Pendekatan energi, dimana variasi energi regangan dari suatu sistem struktur dihubungkan dengan perubahan frekuensi alamiahnya, (b) Pendekatan fisik, dimana perubahan properti kekakuan dan massa suatu sistem struktur dihubungkan oleh perubahan frekuensi alamiahnya dan juga perubahan ragam getarnya.

Aplikasi metode elemen hingga dengan metode Ritz untuk identifikasi kerusakan struktur telah dilaporkan oleh Gharighoran dkk (2008). Teknik singular value decomposition dipakai untuk mendapatkan index kerusakan struktur. Index tersebut dilaporkan sensitif terhadap perubahan karakterisik dinamik struktur. Studi numerik dilakukan dan hasilnya menunjukkan bahwa metode yang digunakan dapat mendeteksi lokasi dan besar kerusakan pada struktur yang diteliti.

Cundy (2003) melaporkan bahwa metode berbasis response surface metamodel (RSM) dapat digunakan untuk mengidentifikasi kerusakan yang terjadi pada sistem struktur linier maupun tidak liner. Menurut Cundy salah satu keunggulan dari metode RSM adalah metode ini memerlukan sedikit sekali informasi tentang sistem struktur untuk 
mendapatkan indikator kerusakan dari response struktur.

Lee dkk (2004) menggunakan jaringan saraf tiruan untuk identifikasi kerusakan pada struktur. Ratio perbedaan bentuk ragam antara struktur dalam kondisi utuh dan terdapat kerusakan digunakan sebagai input pada metode berbasis jaringan saraf tiruan. Lee dkk menyimpulkan bahwa metode yang mereka gunakan efektif untuk diaplikasikan pada model numerik struktur dan pada model uji di laboratorium.

$\mathrm{Xu}$ dan $\mathrm{Wu}$ (2007) menggunakan data dari respons fungsi frekwensi untuk identifikasi struktur. Perubahan energi dan perubahan kelengkungan bentuk ragam dipakai sebagai indikator kerusakan struktur. $\mathrm{Xu}$ dan $\mathrm{Wu}$ menyimpulkan bahwa metode yang mereka gunakan dapat mendeteksi lokasi dan besar kerusakan yg terjadi.

Wahab dan Roeck (1999) melaporkan hasil riset deteksi kerusakan pada jembatan dengan menggunakan perubahan kelengkungan pada berbagai bentuk ragam. Penggunaan cara Lanczos untuk memperoleh parameter modal yang lebih akurat diusulkan oleh Dutta dan Talukdar (2002). Kerusakan struktur diidentifikasi dari perubahan frekwensi alamiah dan turunan dari bentuk ragam. Abdo dan Hori (2002) melakukan studi numerik untuk mendapatkan indikator kerusakan pada struktur. Mereka menyimpulkan bahwa bentuk ragam sudut rotasi (rotational mode shape) berpotensi sebagai indikator lokasi kerusakan struktur.
Susanto dan Budipriyanto (2013) mempresentasikan hasil studi deteksi kerusakan pada jembatan baja. Kerusakan disimulasikan terjadi di satu lokasi saja pada struktur utama jembatan baja yang diteliti.

Dalam makalah ini, dipresentasikan hasil studi numerik yang dilakukan untuk deteksi kerusakan struktur atas jembatan baja kereta api, serta penentuan sensor percepatan yang optimal agar diperoleh respons struktur sesuai dengan target ragam yang dikendaki. Studi ini merupakan kelanjutan dari studi yang sebagian hasilnya telah disajikan pada Susanto dan Budipriyanto (2013).

Metode deteksi kerusakan yang digunakan pada studi ini adalah metode deteksi berdasarkan respons struktur jembatan akibat beban dinamis kereta api yang melintas diatasnya. Kerusakan disimulasikan terjadi di beberapa lokasi pada struktur atas jembatan kereta api. Studi kasus dari studi ini adalah jembatan kereta api Porong - Sidoarjo yang merupakan salah satu jembatan tua yang dibangun sejak era kolonial Belanda, lihat Gambar 1. Sampai sekarang jembatan tersebut masih digunakan untuk lalu lintas kereta api dari Surabaya menuju Malang dan kota-kota lain serta sebaliknya.

\section{Metodologi}

Pada struktur dengan satu derajat kebebasan, persamaan gerakannya dapat dituliskan sebagai berikut (Wilson, 1981):

$$
\ddot{y}(t)+2 \zeta \omega \dot{y}(t)+\omega^{2} y(t)=f(t) \ldots \ldots \ldots .
$$




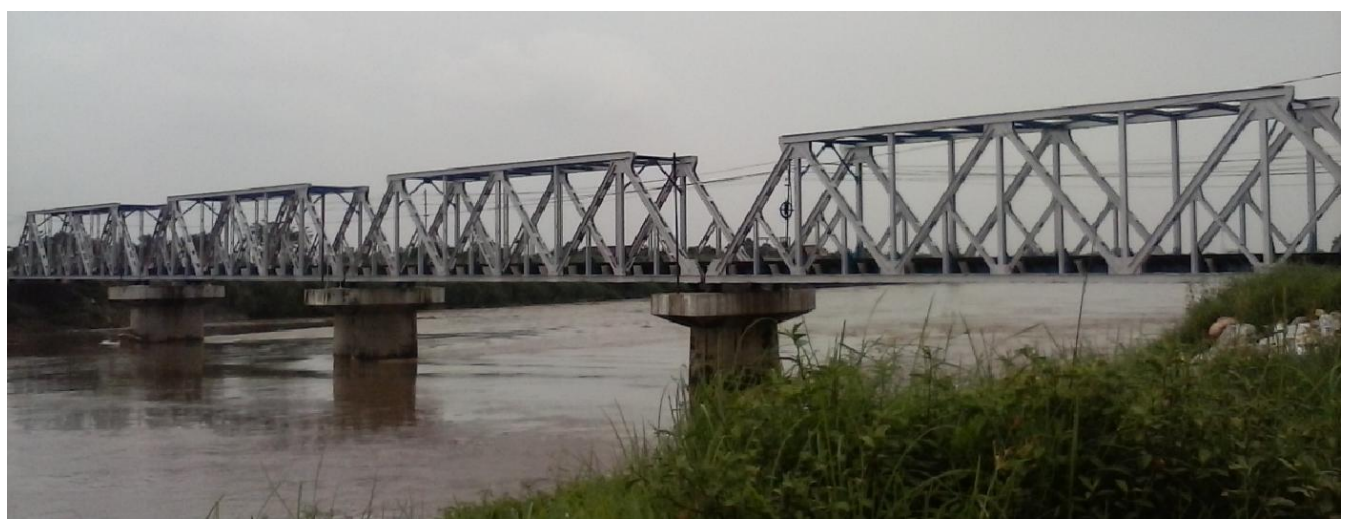

Gambar 1. Foto jembatan kereta api di Porong, Kabupaten Sidoarjo

$y(t)$ adalah displacement, $y(t)$ adalah kecepatan, $\ddot{y}(t)$ adalah percepatan, $\zeta$ adalah faktor redaman, $\omega$ adalah frekuensi angular, dan $f(t)$ adalah input getaran. Total percepatan dari suatu unit massa dengan sistem derajat kebebasan tunggal adalah

$f(t)_{T}=\ddot{y}(t)+f(t)$

Persamaan (1) dapat diselesaikan dengan melakukan substitusi $\ddot{y}(t)$ ke dalam persamaan (2) menjadi persamaan berikut:

$f(t)_{T}=-\omega^{2} y(t)-2 \zeta \omega y(t)$

Jika nilai redaman sangat kecil, maka formula pada persamaan (5) dapat diabaikan dan total percepatan sistem sama dengan $\omega^{2} y(t)$. Maka respons dari gerakan akibat beban kendaraan, $S(\omega)$ dapat ditulis menjadi:

$S(\omega)=\omega^{2} y(\omega)_{M A}$

S( $\omega)$ adalah pseudo-spektrum pecepatan (Pseudo Spectral Acceleration - PSA) . Pada makalah ini, Si $\omega)$ digunakan sebagai parameter indikasi kerusakan pada struktur.

Penentukan posisi sensor akselerometer yang optimal dalam uji dinamik struktur jembatan ini dilakukan dengan pendekatan yang diusulkan oleh Kammer (1991). Menurut Kammer lokasi sensor dapat ditentukan dari matriks, $E$

$E=\Phi_{s}\left[\Phi_{s}^{T} \Phi_{s}\right]^{-1} \Phi_{s}^{T}$.

$\Phi_{s}$ adalah ragam target pada titik lokasi sensor, $T$ dan -1 menyatakan masingmasing transpos dan invers matriks.

Elemen diagonal matriks E, $E_{i i}$ dapat dituliskan sebagai

$E_{i i}=\rho_{i}^{T} \lambda^{-1} \rho$

Dengan $\rho_{i}$ adalah vektor kolom yang memuat baris ke $i$ dari matriks $\Phi_{s}$ dan $\lambda$ adalah nilai eigen dari Fisher information matrix, $A_{0}$. Kisaran nilai elemen matrik $E_{i i}$ adalah

$0,0 \leq E_{\mathrm{ii}} \leq 1.0$

Nilai $E_{i i}=0$ menunjukkan bahwa target ragam tidak dapat dipantau dari lokasi sensor terkait sedang nilai $E_{i i}-1$ menunjukkan bahwa target ragam dapat diidentifikasi oleh sensor dari lokasi terkait. Penjelasan lebih lengkap mengenai teori penempatan sensor yang dipakai dalam studi ini dapat dilihat pada Kammer (1991). 
Untuk mendapatkan karakteristik dinamik struktur yaitu frekuensi alamiah dan spektrum respons, struktur jembatan dimodelkan secara numerik dan dianalisis dengan bantuan perangkat lunak CSI Bridge V15. Beban dinamis pada struktur jembatan yang diteliti adalah beban lokomotif kereta api jenis CC201 beserta rangkaian gerbongnya.

Pada makalah ini disajikan hasil analisis dinamis struktur dalam kondisi utuh (tidak rusak) dan struktur dalam kondisi rusak. Struktur dalam kondisi utuh dimodelkan sesuai dengan data yang diperoleh dari PT KAI. Kerusakan pada struktur jembatan dimodelkan sebagai pengurangan luas penampang pada elemen rangka struktur. Pada studi ini pengurangan luasan penampang sebesar $10 \%$ digunakan untuk memodelkan kerusakan pada lokasi tertentu pada struktur jembatan.

Kerusakan tersebut disimulasikan terjadi elemen struktur di sekitar titik simpul jembatan bagian bawah. Penentuan lokasi kerusakan didasarkan pada informasi dari Sugiono dan Sulandi (2013). Lokasi kerusakan yang diteliti pada studi ini disajikan pada Gambar 2.

Dengan memodelkan suatu kerusakan berarti sebenarnya sudah diketahui lokasi kerusakannya, namun tujuan utama dari penelitian ini adalah untuk mengetahui letak titik yang paling sensitif untuk mendapatkan hasil perubahan karakteristik dinamis yang diakibatkan oleh adanya kerusakan. Sehingga dengan penempatan sensor pada titik tersebut maka dapat diketahui kondisi struktur apakah masih dalam kondisi utuh atau ada kerusakan, yang ditandai dengan adanya perubahan karakteristik dinamis struktur tersebut.

Studi ini mencoba melihat seberapa besar efek perubahan karakteristik dinamis setelah model struktur diberikan simulasi kerusakan.

\section{Hasil dan Pembahasan}

Pada kondisi struktur utuh (tidak terdapat kerusakan) pengaruh faktor redaman pada struktur serta kecepatan kereta api saat melintas jembatan pada spektrum respons struktur diteliti.

Gambar 3(a) memperlihatkan spektrum respons dari struktur untuk beberapa nilai faktor redaman. Seperti terlihat pada gambar tersebut faktor redaman berpengaruh terhadap nilai spektrum respons; semakin besar faktor redaman nilai puncak respons semakin kecil.

Gambar 3(b) menunjukkan spektrum respons untuk kereta api dengan kecepatan 70 km/jam, 80 km/jam, dan $90 \mathrm{~km} / \mathrm{jam}$. Besar spektrum respons juga dipengaruhi oleh kecepatan kereta api yang lewat jembatan yang diteliti.

Dalam studi ini besar faktor redaman sistem struktur diasumsikan sebesar 2\%. Sedangkan kecepatan kereta api ketika lewat jembatan yang diteliti diambil sebesar $70 \mathrm{~km} / \mathrm{jam}$. Nilai faktor redaman dan kecepatan tersebut dipergunakan untuk keperluan simulasi dalam studi ini. Faktor redaman dan kecepatan kereta api dengan nilai yang lain bisa digunakan untuk simulasi dengan cara yang sama dengan cara yang disajikan dalam makalah ini. 
(a)

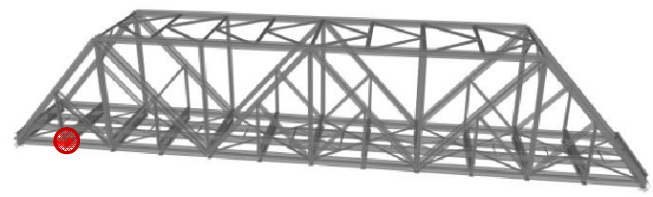

(c)

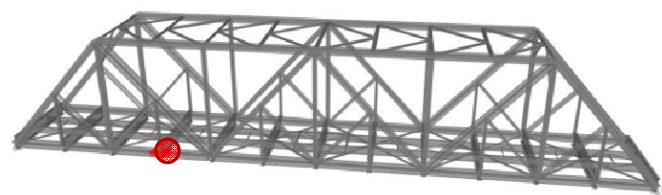

(e)

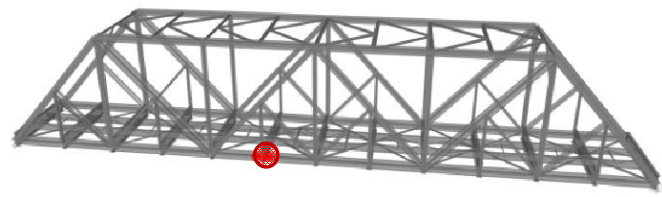

(b)

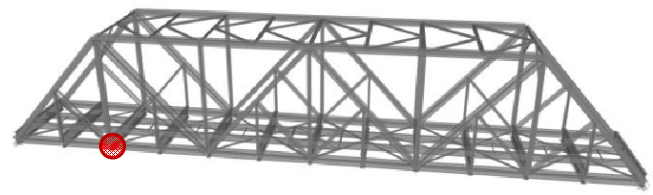

(d)

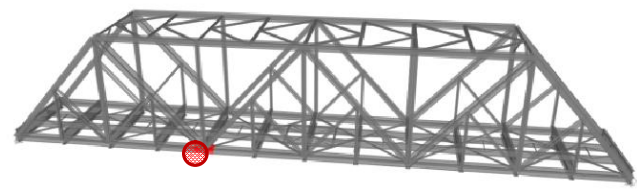

(f)

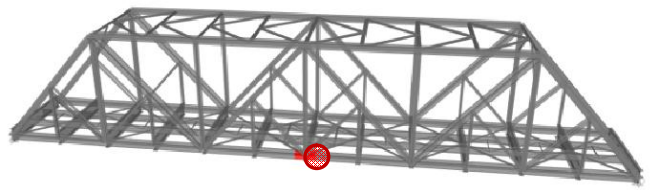

(g)

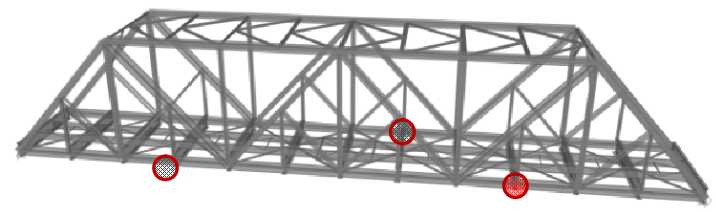

Gambar 2. Lokasi dari skenario kerusakan yang diteliti (ditandai dengan lingkaran) (a), (b),(c),(d),(e),(f) terjadi di 1 (satu) lokasi, dan (g) terjadi di 3 (tiga) lokasi.

Spektrum respons struktur pada kondisi utuh (tidak rusak) dan ada kerusakan (dengan skenario seperti pada Gambar 2) dihitung dengan bantuan perangkat lunak computer. Nilai Pseudo Spectral Acceleration (PSA) yang dihitung dengan Persamaan (4) pada kondisi struktur utuh dan terjadi kerusakan menurut skenario kerusakan 1, 3, 5 (lihat Gambar 2(a) sampai (f)) dan jamak (kerusakan terjadi di 3 (tiga) lokasi sekaligus, lihat Gambar 2(g) diplot pada grafik dengan variabel bebas frekuensi. 
(a)

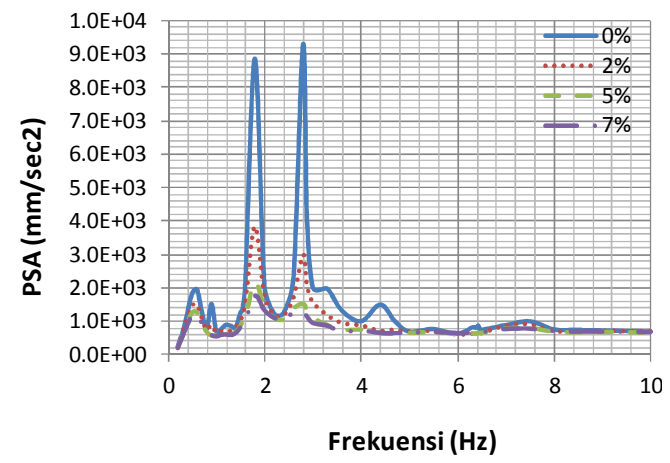

(b)

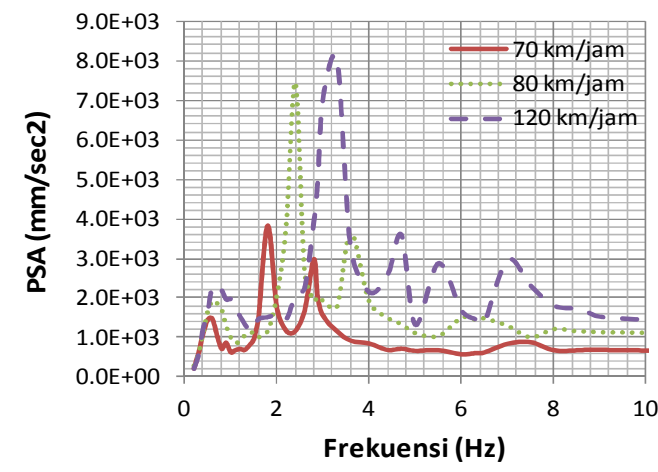

Gambar 3. Pengaruh (a) faktor redaman, dan (b) kecepatan KA terhadap spektrum respons struktur jembatan akibat beban KA saat melewati jembatan.

(a)

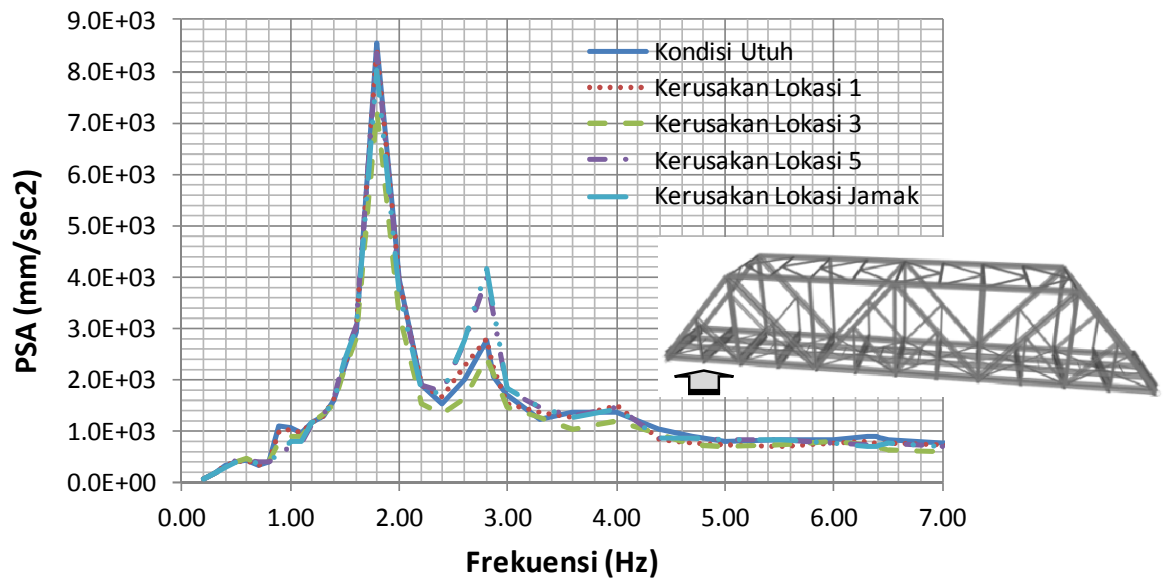

(b)

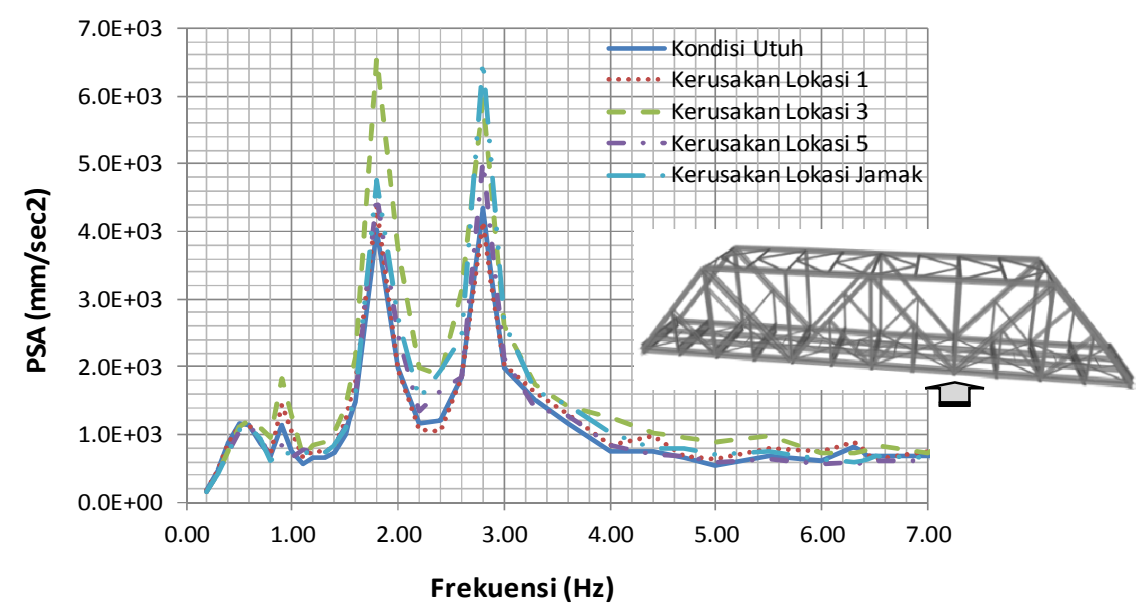

Jurnal APLIKASI: Media Informasi \& Komunikasi Aplikasi Teknik Sipil Terkini 
(c)

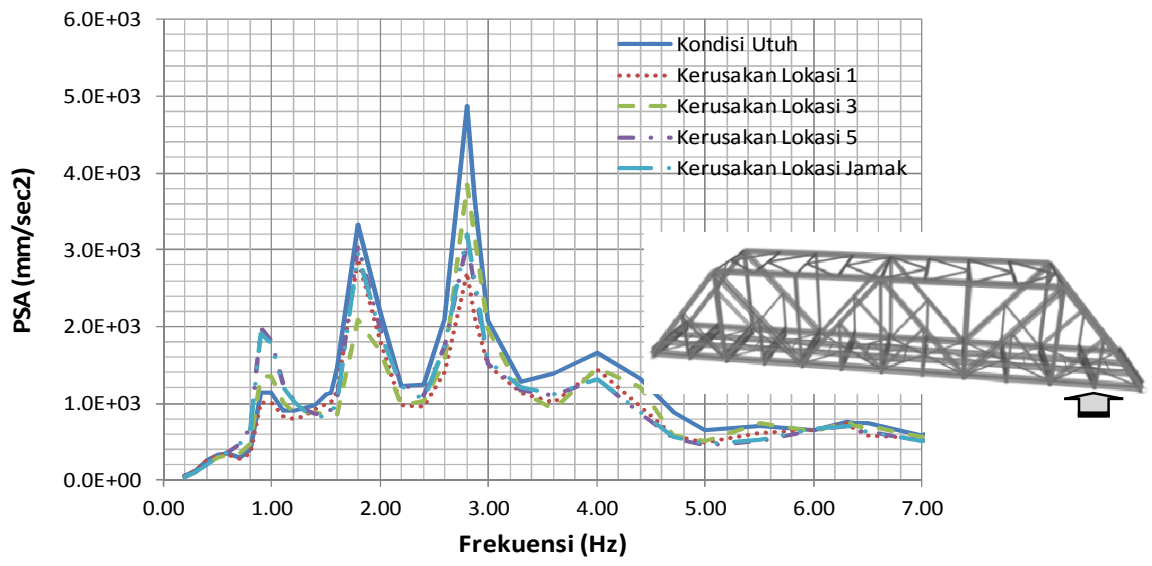

Gambar 4. (a), (b), dan (c) Spektrum respons struktur di titik yang ditandai dengan u untuk berbagai kondisi struktur.

Hasil dari plot grafik tersebut untuk titik no 2, 127, dan 165 (ditandai dengan tanda panah) ditampilkan pada Gambar 4(a), (b), dan (c). Seperti dapat dilihat pada Gambar 4 nilai PSA berubah dari kondisi strukrur utuh dan kondisi terdapat kerusakan pada struktur.

Gambar 5 menyajikan nilai puncak (maksimum) PSA di titik simpul pada jembatan pada kondisi utuh (tidak rusak) dan terdapat kerusakan di lokasi Gambar 2(a). Perubahan nilai PSA pada titik simpul di struktur jembatan tidak sama. Di titik-titik tertentu nilai PSA yang berubah secara signifikan namun di titik yang lain perubahannya relatif tidak signifikan. Walaupun demikian hal penting yang perlu dicatat adalah akibat kerusakan yang diteliti nilai PSA berubah di titik-titik pada struktur jembatan KA yang diteliti sehingga dapat dibedakan kondisi struktur utuh atau rusak.
Berdasarkan kenyataan di atas maka perlu dicari titik-titik pada struktur yang mempunyai nilai dan perubahan respons percepatan struktur (dengan demikian juga nilai PSA) yang cukup signifikan akibat kerusakan sehingga nilai tersebut dapat dimonitor dari titiktitik tersebut. Penentuan titik ini sangat diperlukan pada uji struktur real. Untuk mendapatkan lokasi sensor yang optimal pada struktur yang jembatan KA yang diteliti maka metode yang diusulkan oleh Kammer (1991) diaplikasikan dengan target 28 ragam dan hasilnya disajikan pada Gambar 6 . Dapat dilihat dari Gambar 6, sensor yang optimal untuk kondisi struktur seperti pada Gambar 2 ada di titik simpul 9, 12, 99, 102, 112, 116, 126, 130, 139, dan dan 143. Titik titik dari hasil analisis dengan algorithma yang dijelaskan di metodologi pada beberapa kondisi struktur mempunyai nilai Effective Independence (EFI) sama dengan 1 (lihat Persamaan 6 untuk 
perhitungan EFI) untuk 10 lokasi sensor. Nilai EFI sama dengan 1 menunjukkan bahwa respons dapat dipantau dari titik-titik tersebut.

\section{Simpulan}

Makalah ini membahas tentang deteksi kerusakan struktur jembatan rangka baja kereta api dengan menggunakan spektrum dari respons dinamik struktur akibat beban kereta api saat melewati jembatan. Nilai Pseudo Spectral Acceleration (PSA) digunakan untuk deteksi kerusakan pada struktur yg diteliti.

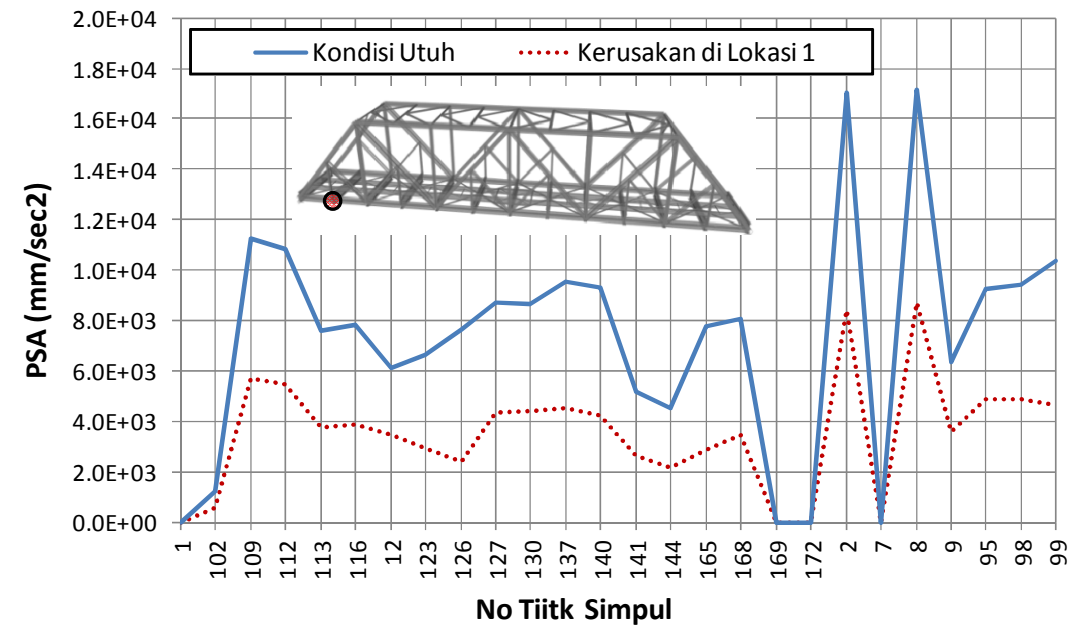

Gambar 5. Nilai puncak (maksimum) PSA pada titik titik simpul struktur jembatan KA yang diteliti pada kondisi utuh (tidak rusak) dan terdapat kerusakan

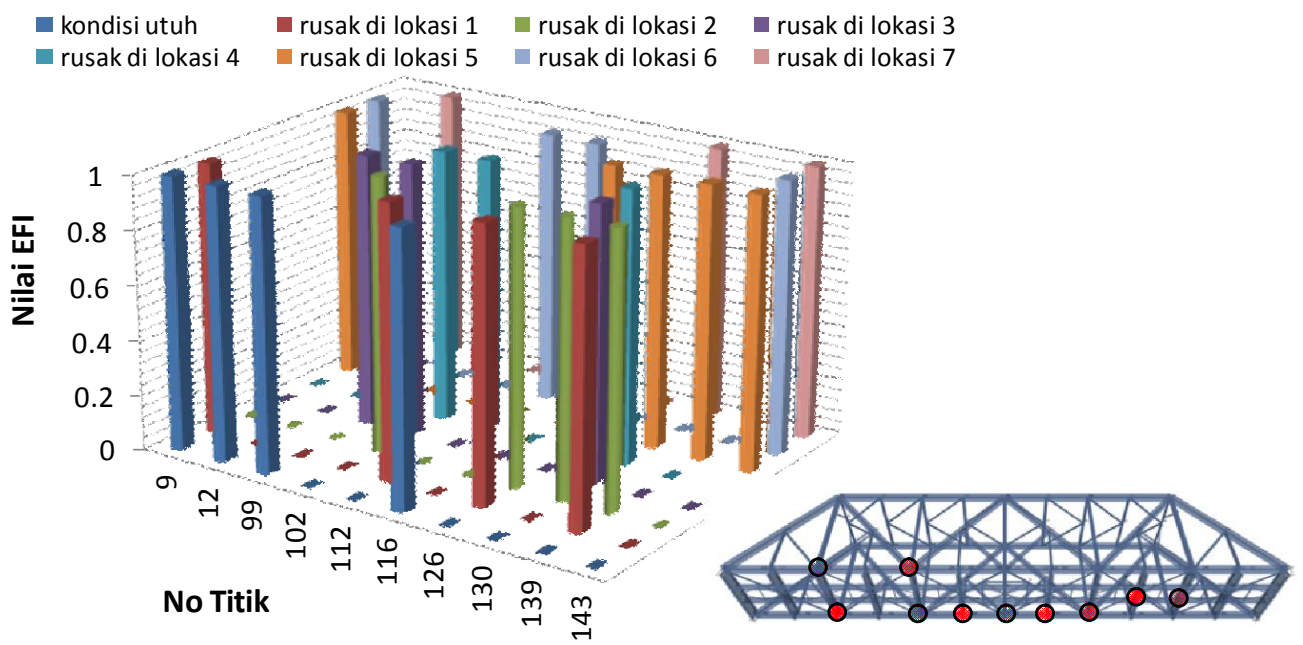

Gambar 6. Penempatan sensor percepatan untuk struktur pada kondisi yang diteliti dengan nilai effective independence (EFI) 
Penempatan sensor percepatan (akselerometer) untuk identifikasi kerusakan struktur juga ditentukan berdasarkan respons dinamis struktur dalam kondisi utuh dan rusak yang disimulasikan. Hasil studi ini menunjukkan bahwa metode yang digunakan dapat mendeteksi adanya kerusakan yang disimulasikan terjadi pada struktur jembatan yang diteliti. Masih diperlukan studi untuk identifikasi lokasi kerusakan struktur jembatan KA berdasarkan nilai PSA serta studi terhadap jenis kerusakan yang lain sehingga metode ini dapat aplikasikan pada struktur real di lapangan.

\section{Daftar Pustaka}

Abdo, M. A. B. dan Hori, M., (2002). A Numerical Study of Structural Damage Detection Using Changes in The Rotation of Mode Shapes, Journal of Sound and Vibration, 251(2), 227-239.

Anonym, (2009), Pedoman Konstruksi dan Bangunan No. 005/BM/2009Pemeriksaan Jembatan Rangka Baja, Kementerian PU, Direktorat Bina Marga.

Cundy, A. L., (2003), Use of Response Surface Metamodels in Damage Identification of Dynamic Structures, Thesis, Master of Science in Engineering Science and Mechanics, Los Alamos National Laboratory, Blacksburg, Virginia.

Dutta, A. Talukdar, S., (2002), Damage Detection in Bridges Using Accurate Modal Parameters, Finite Elements in Analysis and Design, 40, 287-304.
Ge, M., Lui, E. M., (2005), Structural Damage Identification using System Dynamic Properties, Journal Computers and Structures, 83, 2185-2196.

Gharighoran, A. Daneshjoo, F. Khaji, N., (2008), Use of Ritz Method for Damage Detection of Reinforced and Post-Tensioned Concrete Beams, Construction and Building Materials, 23, 2167-2176.

Kammer, D. C., (1991), Sensor Placement for On-Orbit Modal Identification and Correlation of Large Space Structures, Journal of Guidance, Control, and Dynamics, 14, 251-259.

Lee, L. S. Karbhari, V. M. Sikorsky C., (2004), Investigation of Integrity and Effectiveness of RC Bridge Deck Rehabilitation with CFRP Composites, Department of Structural Engineering, University of California, San Diego.

Sugiono dan Sulandi, (2013), PT. Kereta Api Indonesia (Persero), DAOP 8 Surabaya, Komunikasi personal.

Susanto. T., Budipriyanto, A., (2013), Structural Damage Detection of A Steel-Truss Railway Bridge Using its Dynamic Characteristics, Proceedings of the International Seminar on Applied Technology, Science, and Art (4th APTECS), Surabaya, Indonesia.

Wahab, M. M. A. Roeck, G. D., (1999), Damage Detection in Bridges Using Modal Curvatures: Application to A Real Damage Scena- 
rio, Journal of Sound and

Vibration, 226(2), 217-235.

Wilson, E. L., Kiureghian, A. Der, Bayo, E. R., (1981), A Replacement for the SRSS Method in Seismic Analysis, Earthquake Engineering and Structural Dynamics, 9, 187-192.

$\mathrm{Xu}$, Z.D. Wu, Z., (2007), Energy Damage Detection Strategy Based on Acceleration Responses for Long-Span Bridge Structures, Engineering Structures, 29(4), 609-617. 
Halaman 12 Jurnal APLIKASI: Media Informasi \& Komunikasi Aplikasi Teknik Sipil Terkini 